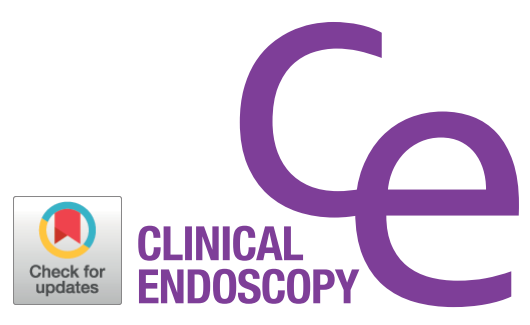

\title{
A Novel Approach for Incisionless Stone Management: Transpapillary Lumen-Apposing Metal Stent for Duct Clearance and Cholangioscopy Access
}

\author{
Vincent Zimmer ${ }^{1,2}$ \\ ${ }^{1}$ Department of Medicine, Marienhausklinik St. Josef Kohlhof, Neunkirchen, ${ }^{2}$ Department of Medicine II, Saarland University Medical Center, \\ Saarland University Homburg, Homburg, Germany
}

A lumen-apposing metal stent (LAMS) is an innovative device recently developed for use in interventional endoscopy, with re-purposed LAMS applications constantly being introduced. ${ }^{1}$ For an increasingly multimorbid population with complicated bile duct stone disease and rigorous indications for dual antiplatelet therapy (DAPT), implying both high procedural and thrombotic risk, endoscopic management strategies vary widely.

Here, I present a novel approach of using upfront transpapillary LAMS for symptomatic stone disease and through-theLAMS direct cholangioscopy (DC) access. Following non-STsegment elevation myocardial infarction and drug-eluting stent implantation in an elderly patient, index endoscopic retrograde cholangiography (ERC) performed six weeks earlier revealed several small bile duct stones, and 7-F plastic stenting was performed. At repeat ERC, a 30×10-mm yoyo-type LAMS (Diabolo stent; Leufen Medical, Berlin, Germany; Fig. 1A) was inserted through the papilla under peri-interventional ceftriaxone and after prophylactic pancreatic duct stenting, with some small stones retained proximal to the stent saddle (Fig. 1B). Using an ultra-slim upper endoscope, through-the-LAMS DC was performed after full stent expansion the next day,

Received: July 22, 2018 Revised: September 4, 2018

Accepted: September 5, 2018

Correspondence: Vincent Zimmer

Department of Medicine, Marienhausklinik St. Josef Kohlhof, Klinikweg 1-5, Neunkirchen 66539, Germany

Tel: 0049-6821-3632070, Fax: 0049-6821-3632624, E-mail: vincent.zimmer@gmx. de

ORCID: https://orcid.org/0000-0002-6298-4717

(c) This is an Open Access article distributed under the terms of the Creative Commons Attribution Non-Commercial License (http://creativecommons.org/ licenses/by-nc/3.0) which permits unrestricted non-commercial use, distribution, and reproduction in any medium, provided the original work is properly cited.

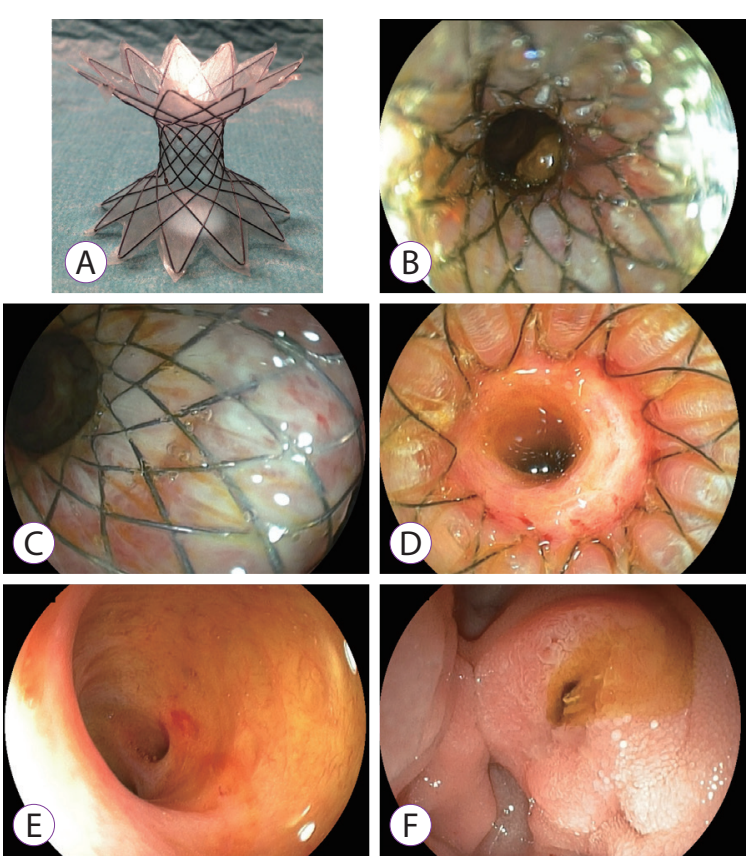

Fig. 1. (A) Ex-vivo presentation of a 30×10-mm yoyo-type lumen-apposing metal stent (LAMS) (flange diameter $25 \mathrm{~mm}$ ) with a more sloping saddle-to-flange angle in contrast to other LAMS types; however, this type is considered favorable for the present and other short-stricture applications (LAMS, Diabolo stent; Leufen Medical, Berlin, Germany). (B) Endoscopic visualization of the LAMS immediately after placement. Note insufficient stent expansion with a retained bile duct stone visible at the LAMS saddle. (C) Direct cholangioscopy images obtained using an ultra-slim upper endoscope (Fujinon EG-530NW; Fujifilm, Düsseldorf, Germany; outer diameter $5.9 \mathrm{~mm}$ ) the following day at the level of the stent entry showing whitened papillary mucosa related to tissue tension owing to radial stent forces. (D) The proximal stent end tightly adapts to the lower bile duct contour, forming a funnel-shaped outlet for spontaneous stone passage. (E) Complete throughthe-LAMS cholangioscopy up to the hilum excluded the possibility of remnant stone disease, such that the LAMS could be removed and extracted orally. $(F)$ The papilla after reinsertion reveals an inconspicuous largely collapsed opening, without signs of hemorrhage and with visible ample spontaneous bile flow. 
showing whitened papillary mucosa due to tissue tension (Fig. 1C), and a tight funnel-shaped adaptation of the proximal stent end to the distal bile duct contour (Fig. 1D). Residual stones were excluded by cholangioscopy, suggesting spontaneous passage after stent expansion (Fig. 1E). Following this, the LAMS was orally extracted without bleeding complications, while the papillary orifice revealed ample spontaneous bile flow (Fig. 1F, Supplementary Video 1). The subsequent course was uncomplicated, and the patient was discharged home.

Metal stenting for the treatment of complex stone disease has been increasingly reported, opening avenues for incisionless procedures with a covered self-expandable metal stent (SEMS) and prolonged stent indwelling duration. ${ }^{2-4}$ In contrast to the reported strategies involving a conventional SEMS, a funnel-shaped LAMS may facilitate spontaneous stone passage and may serve as a temporary incisionless access port to the biliary tract for instrumentation and/or performance of DC. Moreover, transpapillary LAMS use has recently been described for management of post-incision bleeding. ${ }^{5}$ Upfront LAMS use for spontaneous and/or device-assisted duct clearance followed by cholangioscopic confirmation is a novel and appealing approach for management of common bile duct stone disease in patients on DAPT. However, further technique refinement and systematic study are needed.
Conflicts of Interest

The author has no financial conflicts of interest.

Supplementary Material

Video 1. Video documentation of the lumen-apposing metal stent (LAMS) insertion and through-the-LAMS cholangioscopy performed on the next day. Given the innovative complexity and high costs associated with such a procedure, cholangioscopic confirmation of freedom from stones with a very high diagnostic reliability is indicated prior to LAMS extraction, with ensuing collapse of the papillary orifice (https://doi.org/10.5946/ce.2018.131. v001).

\section{REFERENCES}

1. Lightdale CJ. Lumen-apposing metal stents: an important new tool for interventional endoscopy comes of age. Gastrointest Endosc Clin N Am 2018;28:xi-xii.

2. Martin JA. Incisionless stone extraction 2.0: clever, but costly. Gastrointest Endosc 2015;82:724-727.

3. Hartery K, Lee CS, Doherty GA, et al. Covered self-expanding metal stents for the management of common bile duct stones. Gastrointest Endosc 2017;85:181-186.

4. Cho E, Park CH, Jun CH, Kim HS, Choi SK, Rew JS. Self-expandable metal stents for the extraction of common bile duct stones in patients receiving dual antiplatelet agents: a pilot study. Surg Endosc 2018;32:1077-1081

5. Donatelli G, Dumont JL, Derhy S, et al. New indications for fully covered lumen-apposing metal stents: biliary stenting to treat post-sphincterotomy bleeding or ampullary stenosis. Endoscopy 2018;50:E36-E37. 